\title{
Commentary: Effects of psilocybin on time perception and temporal control of behavior in humans
}

\author{
Katarina L. Shebloski ${ }^{1 *}$ and James M. Broadway ${ }^{2}$ \\ ${ }^{1}$ Department of Psychology, University of California, Santa Barbara, Santa Barbara, CA, USA, ${ }^{2}$ Department of Neuroscience, \\ University of New Mexico, Albuquerque, NM, USA
}

Keywords: subjective time perception, temporal processing, psilocybin, 5-HT2A receptor, schizophrenia, serotonin, altered states of consciousness

\section{A commentary on}

Effects of psilocybin on time perception and temporal control of behavior in humans by Wittmann, M., Carter, O., Hasler, F., Cahn, B. R., Grimberg, U., Spring, P., et al. (2007). J. Psychopharmacol. 21, 50-64. doi: 10.1177/0269881106065859

\section{INTRODUCTION}

OPEN ACCESS

Edited by:

Daya Shankar Gupta,

Camden County College, USA

Reviewed by:

Irene Alustiza,

Clínica Universidad de Navarra, Spain

Rainer Krähenmann

University of Zurich, Switzerland

*Correspondence:

Katarina L. Shebloski

kshebloski1992@gmail.com

Specialty section

This article was submitted to

Perception Science,

a section of the journal

Frontiers in Psychology

Received: 05 March 2016

Accepted: 03 May 2016

Published: 19 May 2016

Citation:

Shebloski KL and Broadway JM

(2016) Commentary: Effects of

psilocybin on time perception and

temporal control of behavior in

humans. Front. Psychol. 7:736.

doi: 10.3389/fpsyg.2016.00736
We discuss Wittmann et al. (2007) "Effects of Psilocybin on Time Perception and Temporal Control of Behavior in Humans," proposing that altered states of consciousness induced by pharmacological treatments and neurological disorders can reveal much about the circuitry underlying time perception in normal states of consciousness. Further research is needed to integrate these separate research domains.

The brain integrates partial sensory input with internal representations to construct the elaborate story we know as time (Hammond, 2012). Our ordinary experiences reveal the complicated game the mind can play with perceived time: the day drags when we are bored, yet slips through our fingers when distracted or amused. Despite varying phenomenological experiences of time, the appropriate integration of physical time with functional behavior requires a sufficiently accurate perception structured by the conceptual framework of past, present, and future (Eagleman et al., 2005). Working memory, attention, and executive control support this integrated construction (Fuchs, 2007; Marchetti, 2014). Effects on human time perception are observed when these cognitive systems are modulated by pharmacological treatments or psychiatric disorders (González-Maeso and Sealfon, 2009), suggesting the presence of a neurophysiological process that is intrinsic to temporal information processing (Rammsayer, 2008).

\section{PSILOCYBIN AND TEMPORAL PROCESSING IN NORMAL SUBJECTS}

Serotonergic hallucinogens generally slow the perceived flow of time (Shanon, 2003). Pharmacological manipulations using psilocybin have shed light on mechanisms responsible for this distorted time experience. Wittmann et al. (2007) investigated time estimation under the influence of psilocybin. The study addressed the functional role of serotoninergic $5-\mathrm{HT}_{2 \mathrm{~A}}$ receptors in internal clock models (ICMs) in duration discrimination and temporal control of motor performance. The study revealed a decreased ability to accurately produce intervals longer than $3 \mathrm{~s}$ and synchronize finger-tapping to auditory beats separated by more than $2 \mathrm{~s}$. This suggests that effects of psilocybin on temporal processing are specific to relatively long durations, attributable to 
memory, and decision-making components of the ICM (Gibbon et al., 1984; Block and Zakay, 1996; Rammsayer, 2008; Allman and Meck, 2012), rather than to more basic pacemaker/accumulator mechanisms (Wittmann et al., 2007).

Comparable results are observed in Wackermann et al. (2008), assessing psilocybin duration reproductions of intervals between 1.5 and $5 \mathrm{~s}$. The analyses rely on the "dual klepsydra" model (DKM), a contemporary alternative to the ICM. In the study, the DKM model is applied to Wittmann et al. (2007) data as well as new data. Results indicate temporal processing influenced by psilocybin are dose-dependent (Wackermann et al., 2008).

Temporal processing of longer durations is impaired in people with schizophrenia (Fuchs, 2005; Bonnot et al., 2011). However, recent meta-analyses suggest that timing deficits in schizophrenia generalize across sub- and supra-second intervals, as well as across perceptual and motor tasks; and are independent from more generalized cognitive impairments (Alústiza et al., 2016; Ciullo et al., 2016). The employment of psychoactive substances may be a useful approach to understanding temporal processing in both the ordinary brain and that which is affected by psychiatric disorders.

\section{5-HT $2 A$ RECEPTORS AND TEMPORAL PROCESSING IN SCHIZOPHRENIA}

Psychopharmacological research suggests that drugs such as psilocybin may serve as useful tools for understanding temporal serotonergic signaling mechanisms underlying psychosis, due to their capacity to cause distorted perception in normal subjects (Rammsayer, 2008; González-Maeso and Sealfon, 2009). Modulated $5-\mathrm{HT}_{2 \mathrm{~A}}$ receptor agonists may induce clinical symptoms of schizophrenia such as hallucinations, delusion, psychomotor poverty, and distorted perception (Teixeira et al., 2013), including distorted time perception (Allman and Meck, 2012). Pharmaceutical alterations of $5-\mathrm{HT}_{2 \mathrm{~A}} \mathrm{R}$ activation have shown to assist NMDAR-dependent memory mechanisms (Zhang and Stackman, 2015), and demonstrate that altered time perception is a defining characteristic in schizophrenia due to cognitive changes from NMDA receptor antagonists (Ciullo et al., 2016). Additionally, dopamine-release manipulations cause motor and cognitive defects seen in schizophrenia (Raote et al., 2007), and impair duration discrimination in healthy subjects (Wittmann, 2009). Likewise, schizophrenia is associated with poor accumulation of signal durations derived from impairments in sensory integration (Allman and Meck, 2012; Teixeira et al., 2013). Sysoeva et al. (2010) found that genotypes characterized by higher 5-HT transmission exemplify a higher "loss rate" of duration representation, which may correlate to the very high $5-\mathrm{HT}_{2 \mathrm{~A}} \mathrm{R}$ occupancy in the prefrontal cortex of schizophrenic patients (Zhang and Stackman, 2015).

\section{REFERENCES}

Allman, M. J., and Meck, W. H. (2012). Pathophysiological distortions in time perception and timed performance. Brain. 135, 656-677. doi: 10.1093/brain/awr210
Impairments in working memory, selective attention, and executive control, as seen in schizophrenia, lead to distorted sequencing and integration of past, present, and future into a personal narrative. Carter et al. (2005) demonstrate a reduction in attentional tracking abilities affected by psilocybin, and implicate 5 -HT receptors in these processes through pretreatment of the $5-\mathrm{HT}_{2 \mathrm{~A}}$ receptor antagonist ketanserin.

\section{PROPOSAL FOR INTEGRATIVE RESEARCH}

$5-\mathrm{HT}_{2 \mathrm{~A}}$ receptor activity is associated with time distortion in both psychiatric disorders and hallucinogenic experiences. Manipulating antagonists/agonists provides an approach to utilizing psychoactive drugs as tools in research for understanding time perception in the ordinary brain. It would be fruitful to compare healthy subjects under the influence of psilocybin with patients with acute schizophrenia, utilizing a common paradigm as in Wittmann et al. (2007). However, Wittmann et al. (2007) excludes significant moderating factors of time estimation: attention and emotion (Droit-Volet and Meck, 2007). An fMRI test of acute treatment with psilocybin in healthy volunteers found decreased amygdala reactivity during emotion processing (Kraehenmann et al., 2015). Negative pictures led to an overestimation of duration, indicating greater attention allotted to emotional valence (Wittmann, 2009).

Neuroimaging techniques combined with psychophysical tests of time perception (for a review see Grondin, 2010), including manipulations to assess attentional and emotional factors, will illuminate neural activity responsible for temporal processing in schizophrenia and psychedelic perceptions. Comparing performance and brain activities in these altered states with those of untreated healthy subjects under the same experimental conditions will elucidate mechanisms underlying time perception.

\section{CONCLUSION}

Slowing of perceived time is induced by psilocybin and schizophrenia; having a common basis in $5-\mathrm{HT}_{2 A}$ receptor activities. Commonalities across pharmacological treatments and neurological disorders should be explored within a common experimental paradigm to better understand neurochemical processes mediating temporal processing in ordinary states.

\section{AUTHOR CONTRIBUTIONS}

KS obtained comprehensive research and drafted original article, with collaboration of JB's efforts. JB provided substantial advisory of research materials and writing processes. Both authors edited and revised the article, insured the integrity of the product, and agreed on the final version for submission.

Alústiza, I., Radula, J., Albajes-Eizagirre, A., Domíngue, M., Aubá, E., and Ortuño, F. (2016). Meta-analysis of functional neuroimaging and cognitive control studies in schizophrenia: Preliminary elucidation of a core dysfunctional timing network. Front. Psychol. 7:192. doi: 10.3389/fpsyg.2016. 00192 
Block, R. A., and Zakay, D. (1996). "Models of psychological time revisited," in Time and Mind, ed H. Helfrich (Seattle, WA: Hogrefe and Huber), 171-195.

Bonnot, O., Montalembert, M., Kermarrec, S., Botbol, M., Walter, M., and Coulon, N. (2011). Are impairments of time perception in schizophrenia a neglected phenomenon? J. Physiol. Paris 105, 164-169. doi: 10.1016/j.jphysparis.2011.07.006

Carter, O. L., Burr, D. C., Pettigrew, J. D., Wallis, G. M., Hasler, F., and Vollenweider, F. X. (2005). Using psilocybin to investigate the relationship between attention, working memory, and the serotonin $1 \mathrm{~A}$ and $2 \mathrm{~A}$ receptors. J. Cogn. Neurosci. 17 1497-1508. doi: 10.1162/089892905774 597191

Ciullo, V., Spalletta, G., Caltagirone, C., Jorge, R. E., and Piras, F. (2016). Explicit time deficit in schizophrenia: Systematic review and meta-analysis indicate it is primary and not domain specific, Schizophrenia. Bulletin 42, 505-518. doi: $10.1093 / \mathrm{schbul} / \mathrm{sbv} 104$

Droit-Volet, S., and Meck, W. H.,(2007). How emotions colour our perception of time. Trends Cogn. Sci. 11, 504-513. doi: 10.1016/j.tics.2007.09.008

Eagleman, D. M., Tse, P. U., Buonomano, D., Janssen, P., Nobre, A. C., and Holcombe, A. O. (2005). How subjective time relates to neural time. J. Neurosci. 25, 45. doi: 10.1523/JNEUROSCI.3487-05.2005

Fuchs, T. (2005). Corporealized and disembodied minds a phenomenological view of the body in melancholia and schizophrenia. Philos. Psychiatr. Psychol. 12, 95-107.

Fuchs, T. (2007). The temporal structure of intentionality and its disturbance in schizophrenia. Psychopathology 40, 229-235. doi: 10.1159/000101365

Gibbon, J., Church, R. M., and Meck, W. H. (1984). Scalar timing in memory. Ann. N. Y. Acad. Sci. 423, 52-77. doi: 10.1111/j.1749-6632.1984.tb2 3417.x

González-Maeso, J., and Sealfon, S. C. (2009). Psychedelics and schizophrenia. Trends Neurosci. 32, 225-232. doi: 10.1016/j.tins.2008.12.005

Grondin, S. (2010). Timing and time perception: A review of recent behavioral and neuroscience findings and theoretical directions. Atten. Percept. Psychophys. 72, 561-582. doi: 10.3758/APP.72.3.561

Hammond, C. (2012). Time Warped: Unlocking the Mysteries of Time Perception. Toronto, ON: House of Anansi Press.

Kraehenmann, R., Preller, K. H., Scheidegger, M., Pokorny, T., Bosch, G. O, Seifritz, E., et al. (2015). Psilocybin-induced decrease in amygdala reactivity correlates with enhanced positive mood in healthy volunteers. Biol. Psychiatry 78, 572-581. doi: 10.1016/j.biopsych.2014. 04.010
Marchetti, G. (2014). Attention and working memory: two basic mechanisms for constructing temporal experiences. Front. Psychol. 5:880. doi: 10.3389/fpsyg.2014.00880

Rammsayer, T. H. (2008). Neuropharmacological Approaches to Human Timing. Psychology of Time. Bingley: Emerald Group Publishing Lmtd.

Raote, I., Bhattacharya, A., and Panicker, M.M. (2007). "Serotonin 2A (5-HT2A) receptor function:ligand- dependent mechanisms and pathways," in Serotonin Receptors in Neurobiology. Available online at: http://www.ncbi.nlm.nih.gov/books/NBK1853/

Shanon, B. (2003). Altered states and the study of consciousness- the case of Ayahuasca. J. Mind Behav. 24, 125-154.

Sysoeva, O. V., Tonevitsky, A. G., and Wackermann, J. (2010). Genetic determinants of time perception mediated by the serotonergic system. PLoS ONE 5:e12650. doi: 10.1371/journal.pone.0012650

Teixeira, S., Machado, S., Paes, F., Velasques, B., Silva, J. G., Sanfim, A. L., et al. (2013). Time perception distortion in neuropsychiatric and neurological disorders. CNS Neurol. Disord. Drug Targets 12, 567-582. doi: $10.2174 / 18715273113129990080$

Wackermann, J., Wittmann, M., Hasler, F., and Vollenweider, F. X. (2008). Effects of varied doses of psilocybin on time interval reproduction in human subjects. Neurosci. Lett. 435, 51-55. doi: 10.1016/j.neulet.2008.02.006

Wittmann, M. (2009). The inner experience of time. Philos. Trans. R. Soc. 364, 1955-1967. doi: 10.1098/rstb.2009.0003

Wittmann, M., Carter, O., Hasler, F., Cahn, B. R., Grimberg, U., Spring, P., et al. (2007). Effects of psilocybin on time perception and temporal control of behavior in humans. J. Psychopharmacol. 21, 50-64. doi: $10.1177 / 0269881106065859$

Zhang, G., and Stackman, R. W. (2015). The role of serotonin 5-HT $2 \mathrm{~A}$ receptors in memory and cognition. Front. Pharmacol. 6:225. doi: 10.3389/fphar.2015.00225

Conflict of Interest Statement: The authors declare that the research was conducted in the absence of any commercial or financial relationships that could be construed as a potential conflict of interest.

Copyright $(2016$ Shebloski and Broadway. This is an open-access article distributed under the terms of the Creative Commons Attribution License (CC BY). The use, distribution or reproduction in other forums is permitted, provided the original author(s) or licensor are credited and that the original publication in this journal is cited, in accordance with accepted academic practice. No use, distribution or reproduction is permitted which does not comply with these terms. 